\title{
Doação e ser
}

\section{Martina Korelc*}

Resumo: $\mathrm{O}$ artigo investiga a interpretação que Marion faz da compreensão husserliana da relação entre ontologia e fenomenologia, entre doação e ser. $\mathrm{O}$ autor objeta a Husserl a redução do sentido do ser ao ser dos objetos e propõe primeiramente uma concepção do fenômeno e da subjetividade que dispensa o ser. Na medida, porém, em que se aprofunda o conceito da doação, capaz de evidenciar e superar os limites da associação entre objetividade e fenômeno, muda a concepção do ser, sobretudo do ser da subjetividade e o seu papel no aparecer. Argumento que há razões para voltar a perguntar sobre o ser a partir da primazia fenomenológica da doação.

Palavras-chave: Doação. Ser. Fenômeno. Subjetividade.

\section{Donation and being}

Abstract: The paper examines a Marion's interpretation of a relation between donation and being in Husserl. The author disagrees with Husserl on the identification of the meaning of being with objective being and proposes, at first, a concept of phenomenon and of subjectivity without being. But the development of the meaning of donation leads to the concept of phenomenon not limited to objectivity; the concept of being changes, as well as the comprehension of subjectivity and its role in the appearing of phenomena. I argue that there are reasons to investigate about being on the basis of the phenomenological primacy of donation.

Keywords: Donation. Being. Phenomenon. Subjectivity.

* Doutora em Filosofia pela Pontifícia Universidade Católica do Rio Grande do Sul (PUCRS). Professora da Faculdade de Filosofia da Universidade Federal de Goiás (UFG), Campus Samambaia, Goiânia. E-mail: martina.ufg@gmail.com 


\section{Donazione e essere}

Riassunto: Il testo presenta l'interpretazione che Jean-Luc Marion fa della relazione tra ontologia e fenomenologia e tra donazione ed essere in Husserl. Il suddetto autore contesta a Husserl la riduzione del senso dell'essere all'essere deglio ggetti e propone inizialmente una concezione del fenomeno e della soggettività senza l'essere. Peró, nella misura in cui si approfondisce il concetto della donazione, atto ad evidenziare e superare i limiti dell'associazione tral'oggettività e il fenomeno, cambia la concezione dell'essere, soprattutto dell'essere della soggettività e il suo ruolo nel processo dell'apparire. Sostengo checi sono buone ragioni per ritornare alle domande sull'essere a partire dalla priorità fenomenologica della donazione.

Parole chiavi: Donazione. Essere. Fenomeno. Soggettività.

\section{Introdução}

No presente texto, proponho-me a pensar como a questão do ser é abordada em alguns textos de Jean-Luc Marion, na sua discussão com a concepção de Husserl. O autor detecta um princípio idealista em Husserl, que marca a concepção do ser, e mesmo sem discuti-lo explicitamente, propõe-lhe uma alternativa na elucidação do aparecer dos fenômenos. O conceito de doação, de Marion, pode oferecer uma via para repensar o sentido do ser, mesmo que o autor não se tenha proposto a fazê-lo. A minha leitura dos seus textos, nomeadamente de Réduction et donation (RD), Le visible et le Révélé (VR), Étant donné (ED) e De surcroit (DS), foi por isso atenta ao que o autor diz sobre a questão do ser em Husserl e como a problematização da doação por Marion responde às possibilidades e às limitações do pensamento husserliano a este respeito. Marion é primeiramente crítico em relação à vinculação da fenomenologia à ontologia, sugerindo, "levinasianamente", a pensar a subjetividade sem o ser. A partir de Étant donné, porém, vemos uma sutil reorientação desta crítica para a problematização do conceito de doação como o princípio elucidativo do aparecer dos fenômenos e do seu sentido e assim para a 
consideração da própria ontologia, ou da questão do ser, como fundada na doação, ou melhor, provinda dela; o esforço do autor se concentra em mostrar ou desencobrir a doação como o princípio anterior ao ser e à constituição do mundo por parte da subjetividade transcendental. Após apresentar brevemente estas teses, na terceira parte do artigo apresento as consequências desta descoberta da doação para a concepção da subjetividade. No fim, tento justificar a volta da problematização do sentido do ser, pensado agora a partir da doação; o sentido desta tentativa é a convicção de que a reflexão rica de Marion oferece algum elemento novo para contornar a leitura idealista do ser com a qual a fenomenologia de Husserl sempre de novo esbarra.

Nas palavras de Marion, a doação é um conceito encontrado no pensamento de Husserl, embora ele nunca a definiu - porque ela mesma define todo o resto, o fenômeno, imanência e transcendência, a coisa mesma, a redução... Por isso, "a doação joga um papel tão radical que reproduz a aporia do ser na metafísica: para o definir, é preciso já pressupô-lo" (ED, p. 41). Pensar esta vizinhança entre doação e ser é o objetivo deste artigo.

1.

Em Réduction et donation, o autor analisa a relação entre fenomenologia e ontologia; ele evidencia assim que é legítimo perguntar por uma concepção de ser em Husserl e que a crítica, motivada pelos escritos de Heidegger, de que Husserl teria deixado o problema do ser impensado, não se justifica nos textos de Husserl. Em Husserl opera uma concepção e uma problematização do ser, embora Marion a considere insuficiente. A própria fenomenologia é definida por Husserl como ontologia: como exemplo, pode ser mencionado um escrito de 1924, publicado como anexo em Erste Philosophie, intitulado "Idee der vollen Ontologie", no qual ela é definida como ciência transcendental da constituição do mundo, que deve conduzir à ontologia universal e 
absoluta, enquanto ciência a priori do mundo em geral. Vemos que o ser considerado nesta definição é sobretudo o ser mundano, real; uma sua caracterização muito importante é a de que esse ser corresponde sempre para Husserl ao ser do conhecimento ou o ser que se expressa na predicação. A ontologia trata dos entes na medida em que são conhecidos, substratos da predicação; isto significa que para Husserl os entes são somente na medida em que há juízos que os determinam e lhes dão certa validade. O ser é dito na predicação, no interior do espaço lógico que a fenomenologia não transgride (RD, p. 154). Todos os entes mundanos são relativos uns aos outros, mas uma ontologia completa e universal deve mostrar a fundamentação de todos os entes relativos na subjetividade (Hua VIII, p. 219, nota). O ser da subjetividade deste modo também deve ser problematizado. Marion lembra a este respeito o "princípio idealista" (RD, p. 157) de Husserl, segundo o qual toda objetividade deve ser reconduzida e subordinada à subjetividade, no sentido de ser mostrada a dependência do ser objetivo em relação ao ser da subjetividade: o ser do mundo é um ser para a subjetividade e não possui nenhum 'em si', é mero ser intencional, do qual a consciência põe a existência em suas experiências. À subjetividade, por sua vez, é atribuído um ser absoluto (Hua III, § 49, p. 92-93).

Não posso acompanhar aqui as ricas análises de Marion, atentas também à progressão histórica desta questão em Husserl; limito-me a dizer que para o autor o problema principal da concepção husserliana da fenomenologia como ontologia está em entender um único sentido do ser: ser objetivo, objetivado, constituído como objeto. Certo é que a subjetividade não tem de imediato o mesmo sentido que o mundo. Husserl, numa parte central das Ideen zu einer reinen Phänomenologie, expõe com força e clareza a "distinção eidética fundamental [grundwesentlicher Unterschied]" entre o ser como vivido e o ser como coisa, ou a "diferença de princípio, a mais cardinal que existe em geral [die prinzipielle Unterschiedenheit, die kardinalste, die es überhauptgibt]", entre o modo de ser da consciência e o da realidade (Hua III, § 42, p. 76 
- 77). Por um lado, há o ser que se perfila, por outro lado, o ser que por essência não pode perfilar-se - a diferença consiste, portanto, nos modos distintos de doação que abrem um "abismo de sentido". A consciência mantém a primazia mesmo enquanto ser, porque o ser da consciência é a categoria originária do ser, ou a região originária [Ur kategorie des Seins überhaupt, Urregion], na qual todas as outras regiões se enraízam (Hua III, § 76, p. 141). Se portanto a fenomenologia elucida a fundação de todas as ontologias dirigidas aos objetos no Eu, e se o Eu é anterior ao ser dos objetos, a fenomenologia precede as ontologias; já Husserl teria reconhecido isto, segundo Marion (RD, p. 158, cfr. Hua I, § 59).

Contudo, a Husserl 'escapa' a afirmação - que Marion não lhe perdoa - segundo a qual de ambos, o ser imanente e o ser transcendente, pode ser dito que são, são objeto, e têm conteúdo de determinação objetiva (Hua III, $\S 49$, p. 93). Esta unificação de dois modos de ser, que não podem ser unidos por essência numa e mesma categoria de objeto, somente pode significar uma categoria lógica vazia, como o próprio Husserl reconhece. Mas Marion vê nesta interpretação husserliana do ser uma cegueira para qualquer outro sentido do ser que esteja além do sentido objetivo, além do sentido do ser relacionado ao conhecimento dos objetos. A pergunta pelo modo de ser dos objetos é para Husserl a pergunta pelo acesso à cognição deles, diz o autor. Penso que podemos confirmar isto nos textos de Husserl, quando ele justifica a diferença entre o modo de ser da consciência e o modo de ser da realidade como diferença cognitiva entre dois modos de doação, um absolutamente evidente e outro inadequado por essência, que conduzem a dois modos de posição do ser, posição absoluta e posição contingente, respectivamente, e assim a duas distintas teses sobre o ser (Hua III, $\S \S 42,44,46$ ), a tese necessária da consciência e a tese contingente do ser do mundo.

Esta indeterminação, na fenomenologia de Husserl, do sentido do ser que cabe ao Eu, que apenas por meio de uma categoria lógica vazia pode ser chamado de objeto e ser, conduz Marion a sugerir, em Réduction et donation, que o Eu pode ser pensado sem recorrer à categoria do ser 
e que o Eu não precise primeiramente de ser. Não obstante Husserl não tenha pensado este estatuto não-ontológico do Eu, a fenomenologia, cujas possibilidades são mais originárias do que as suas efetivações históricas, poderia avançar, por uma redução mais radical de todo o ser, para fora do ser, liberando o Eu para transcendências outras que o ser e melhores que esse (RD, p. 165 - 166).

O texto "Metafísica e fenomenologia: uma substituição para a teologia" de 1993, republicado em Le Visible et le Révélé, segue esta sugestão, alargando-a para todo o fenômeno. A partir do princípio dos princípios, anunciado por Husserl em Ideen, que estabelece a intuição doadora como a única justificação do fenômeno, o autor propõe duas teses, sobre a ontologia e sobre o fundamento:

A primeira decorre diretamente da doação: a aparição dos fenômenos se liga sem recorrer (pelo menos necessariamente e em primeira instância) ao ser. Trata-se aqui de uma intuição qualquer, do fato de 'se dar' e da presença carnal; estes três termos bastam para definir a fenomenalidade perfeita de um fenômeno sem recorrer de modo algum por essa razão ao ser, ao ente, ainda menos a um 'conceito objetivo de ente'. A questão que se põe legitimamente é saber se todo fenômeno, enquanto está aparecendo, não se dispensa, pelo menos num primeiro tempo, do ser - fenômeno sem o ser. Em seguida, a fenomenologia poderia se libertar absolutamente não somente de toda metaphysica generalis (ontologia), mas também da questão do ser (Seinsfrage) (VR, p. 86).

Se o fenômeno dispensa do ser, para ser determinado, é porque a doação do fenômeno sempre determina todo o ente já como ente dado, doado, com um 'além da entidade'. "O ente dado designa o ente tal que, para ele, seu ser não equivale de início a possuir seu fundo próprio (ov̉oía), mas a se receber no ser, a receber o ser, ou antes, a receber de ser" (VR, p. 87). A doação indica para Marion nestes textos algo para além do ser e da entidade dos entes, algo melhor do que estes; a fenomenologia que pela redução deve reconduzir o olhar à doação, deve portanto reduzir também o ser ao ser dado. 
O próprio conceito e sentido da doação é pensado pelo autor mais profundamente e radicalmente na obra Étant donné. Essai d'une phénoménologie de la donation, de 1998, e De surcroit. Études sur les phénomènes saturés, de 2001. Penso que a partir deste aprofundamento da doação algo novo sobre o ser possa ser dito.

Como o aprofundamento da doação permite compreender todos os fenômenos, inclusive o ser, de um modo novo? O autor insiste, desde o início da obra, que a fenomenologia pretende mostrar o que aparece, os fenômenos, e não fundá-los ou demonstrá-los, como é a pretensão de toda a ciência, especialmente da metafísica. Ora, o mostrar pode ainda abrigar um perigo de sobrevalorizar o papel metafísico da subjetividade, de assim não liberar os próprios fenômenos e deixá-los aparecerem por si, mas de algum modo condicionados pela subjetividade. "Pois o conhecer provém sempre de mim”, diz o autor (ED, p. 15); por isso a manifestação dos fenômenos, o seu aparecer por si, não é evidente. $\mathrm{O}$ que pretende a fenomenologia, portanto, é deixar que os fenômenos se mostrem, na sua aparição, na sua originariedade incondicionada; a doação é precisamente uma condição não fundadora do fenômeno. Tudo o que se mostra, se mostra na medida em que se dá, e é a doação o último ou o primeiro princípio de elucidação de todos os fenômenos. Na convicção de Marion, a doação e o dado não reclamam nenhum princípio ulterior ao qual deveriam ser reconduzidos, como fundamento ou causa. Nisto, a fenomenologia ultrapassaria a metafísica que exige para sua unidade, enquanto ciência, uma relação de fundamentação ou de causalidade entre um ente privilegiado, Deus, o ente comum e a totalidade de outros entes (VR, p. 79). A doação, por sua vez, "não indica aqui tanto a origem do dado, quanto o seu estatuto fenomenológico" (DS, p. 29).

O papel da redução é crucial na fenomenologia: se ela deve garantir o acesso a um solo indubitável de conhecimento, isto contudo não pode ocorrer de modo a produzir a certeza dos objetos - por nela estarem implicadas condições a priori - mas como uma encenação que abre o espetáculo do fenômeno, na qual o fenômeno chegue a 
ocupar toda a cena e absorver a própria operação da redução (ED, p. 17). A redução libera, sobretudo, o acesso à doação. A doação, portanto, deve dar-se sem intermediário, sem recorrer a outro termo para além da própria doação, em si. $\mathrm{O}$ autor contesta o pressuposto de que um tal princípio originário não poderia aceder ao conceito: "a doação articula racionalmente os conceitos que dizem o fenômeno tal como ele se manifesta" (ED, p. 31).

Marion sublinha constantemente a referência a Husserl e a sua descoberta da doação; contudo, há nele uma sutil mudança na interpretação dos fenômenos, por manter sempre todo o peso dos fenômenos não na consciência, mas na doação que nela acontece. A doação mantém a relação com a evidência, e contudo não é a evidência que doa o fenômeno, ela é apenas o lugar da doação; a origem da doação é o próprio 'si' do fenômeno. Para que na evidência o fenômeno possa aparecer, ela não deve alcançar apenas a vivência, mas dar nela o que não é evidente, nem vivido, o que é uma instância exterior à consciência - precisamente o fenômeno como o não evidente. A doação deve ser pensada na sua dobra em doação e dado - ou doado [donné] - o que seria como um aprofundamento e radicalização da descoberta husserliana da correlação a priori entre a consciência e seus correlatos intencionais. Aliás, Marion escreve que Husserl nunca pôs em questão esta descoberta fundamental, embora a tenha substituído pela dualidade entre noese e noema. Para Husserl, aquilo que aparece coincide com o objeto, e os modos de doação do objeto identificam o próprio aparecer. Isto permite a Husserl, na opinião de Marion, superar a oposição metafísica entre a essência e existência, ou seja, abolir a distinção entre elas diante da doação. Como Husserl escreve em Die Idee der Phänomenologie, a oposição entre a existência e essência não significa outra coisa que dois modos de ser que se anunciam em dois modos de autodoação (Hua II, p. 70). Para Marion, Husserl unifica os dois modos de ser na própria doação, porque também ultrapassa o conceito de ente e se distancia assim da metafísica. 
É por isso ainda que a oposição, também ela metafísica, entre o 'simples pensamento' e a 'realidade efetiva' se absorve, não apenas nas duas faces de uma única correlação de aparição, mas sobretudo na única doação que admiravelmente os põe em obra. [...] Se 'permanecemos perplexos', acrescenta Husserl, é por descobrirmos que não precisamos mais escolher entre objeto (o realismo) e o aparecer (o fenomenismo), mas que um e outro se correlacionam indissoluvelmente numa única doação que os torna possíveis e efetivos, segundo seus papeis distintos (ED, p. 35 - 36).

Esta absorção do ente e da distinção entre essência e existência na doação não é problemática para Marion; ao contrário, ela é fecunda, por permitir a superação de dualidades metafísicas não esclarecidas pela tradição. Ora, vejamos mais de perto a relação entre ser e doação. O que é próprio da doação é que ela não dá apenas o que é realmente imanente à consciência, isto é, as vivências, mas também o que lhes é transcendente, por relacionar a imanência à intencionalidade. A imanência não é pois uma estrita identificação de uma coisa consigo mesma, a identificação da vivência, no seu ser real, com os seus conteúdos; o aparecer, assim, não pode identificar-se com a consciência, a preço de não conseguir fazer aparecer nada outro que a consciência. Pela distinção da imanência intencional em relação à imanência real, o próprio Husserl evidencia como a consciência pode receber, além do aparecer, também o que aparece, o objeto intencional enquanto visado, enquanto o aparecer é sempre ordenado ao que aparece. Isto é em certo sentido a essência da doação.

A doação surge precisamente quando a aparência doa, além de si mesma (imanência real), o objeto que sem ela não poderia aparecer, mesmo que ele não se resuma a ela (imanência intencional); a doação irrompe porque o aparecer da aparência faz-se o aparecer daquilo que aparece; resumindo, ela embarca aquilo que aparece no seu próprio aparecer (ED, p. 39). 
Com isso, segundo Marion, a própria existência da realidade transcendente aparece na medida em que é dada. Apenas resta excluído do aparecer o que não é dado, o que não satisfaz a doação, portanto a existência na medida em que não é percebida. Os objetos aparecem, para Husserl, como sendo, como entes, porque eles não são apenas representados na aparição, mas dados em pessoa, autodados. Ser dado em pessoa é, portanto, ser: "As coisas são e são na aparição e, graças à aparição, são elas mesmas dadas" (Hua II, p. 12)1. Marion adiciona: "Aparecer em pessoa equivale portanto a ser, mas ser pressupõe ser dado" (ED, p. 40). Esta equivalência entre ser e ser dado em Husserl, para Marion, não significa apenas uma compreensão da doação, mas uma determinada concepção do ser. "A redução das categorias metafísicas do ente aos modos de aparecer se confirma pela recondução explícita do fato de ser ao aparecer, e do aparecer ao dado em pessoa. Para ser, um ente deve aparecer, portanto, dar-se" (ED, p. 45). Ora, isto não é tudo. Segundo Marion, em Étant donné, também a doação do ser é marcada, em Husserl, pelo único sentido do ser, o ser dos objetos. Ao falar, em Die Idee der Phänomenologie, sobre o fato de as vivências em geral poderem tornar-se objeto de um puro ver e da reflexão, Husserl diz: "Ela [a vivência] é dada como um ente [Seiendes], como um isto-aí, de cujo ser não faz sentido duvidar" (Hua II, p. 31). Até uma vivência, para se dar, deve aparecer como objeto. É a doação que determina para Husserl o aparecer como ente, como o ser de um objeto. Também o próprio ser, diz Marion - nos limites em que se pode falar do próprio ser na diferença em relação ao ente em Husserl - é determinado pela doação dos objetos,

1 "Die Sachen sind und sind in der Erscheinung und vermöge der Erscheinung selbst gegeben". Marion cita em Étant donné esta passagem duas vezes, e a traduz de dois modos diferentes, conforme o que pretende acentuar: ao falar da doação como condição do ser, diz "As coisas são e são na aparição (Erscheinung) e, graças à própria aparição, são dadas (gegeben) (ED, p. 40). Ao aprofundar, a seguir, o ser como aparecer em pessoa, diz: "As coisas são e são na aparição, e em virtude do aparecer (são) dadas elas mesmas (selbstgegeben)" (ED, p. 45), 
uma vez que Husserl afirma que na vivência, enquanto é e é um isto-aí, temos a "medida última do que significa ser e ser dado" (Hua II, p. 31). Este alcance ôntico-ontológico da doação não deve ser negligenciado, segundo Marion, sobretudo porque é confirmado ulteriormente pela operação de constituição, pensada também à luz da doação pelo próprio Husserl: na fenomenologia trata-se de tornar visível a essência da doação e da autoconstituição dos diversos modos da objetidade. Evidenciando assim a relação da doação com a constituição do ser e do ente, Marion conclui: "Tornar-se um ente depende de um sentido designado pelo jogo da intenção e da intuição, mas esta designação, que única provoca um ente dotado de sentido, lhe advém somente pela doação" (ED, p. 47). Ou seja, o jogo da intenção e da intuição é o modo como Husserl entende a constituição do sentido; o sentido, porém, advém ao ente pela doação e não pela constituição.

O que se conclui disto, segundo Marion? Embora Husserl tenha tratado o ser insuficientemente e confusamente, tratou-o pelo viés da doação. Evidenciando isto, Marion muda, expressamente, a sua consideração sobre a relação entre a fenomenologia e ontologia e sobre o lugar da questão do ser na fenomenologia, em relação à posição assumida nas obras anteriores. ${ }^{2} \mathrm{~A}$ submissão de toda a ontologia à redução não significa a supressão da ontologia, mas a sua recondução à doação, a sua doação sob o aspecto reduzido do ente dado. A verdadeira dificuldade desta concepção husserliana está na imprecisão de como a doação determina o ser e o ente. Primeiramente, a imprecisão está na interpretação do ente como objeto, o que põe em questão não somente a sua entidade, mas sobretudo a sua fenomenalidade, porque obnubila a doação. Em segundo lugar, Husserl regulou também a própria doação pela doação de objetos. Mesmo que o objeto possa se doar e a doação do objeto seja um modo de

2 Marion diz expressamente, numa nota de rodapé na obra Étant donné, que não segue mais todas as conclusões da obra Réduction et donation a respeito da ontologia, porque a insistência unilateral na submissão da ontologia à redução encobre a relação entre a ontologia e a doação. Cfr. ED, p. 47, nota 3. 
doação, nada nos autoriza a assimilar todos os modos de doação à doação de objetos. A doação é ela própria a norma última da fenomenalidade e portanto não pode ser medida ou regulada pela objetividade, que pressupõe um eu da consciência constituindo o fenômeno, visando-o como seu noema (ED, p. 50). Para Marion, portanto, Husserl, embora tenha descoberto a doação, não a liberou para as suas possibilidades de elucidar o aparecer dos fenômenos por si e em si; a objetividade e a entidade, às quais a redução conduziu a fenomenologia, impõem antecipadamente a tudo que é dado condições de possibilidade, impondo ao dado fenomenal uma aparição segundo estes modos de doação.

"O fenômeno sob o modo de objeto e de ente só pode aparecer porque se encontra já dado mais originariamente; objetividade e entidade podem ser pensadas assim como simples variações, legítimas mas limitadas, [...] que se desenham pelo e sobre o fundo da doação" (ED, p. 60).

2.

Antes de avançarmos com a reflexão sobre o ser a partir da doação, convém colher algum aspecto do próprio conceito de doação que pode ajudar a elucidar as possibilidades novas de sentido do ser. Primeiramente, é necessário pensar a doação a partir da sua dobra com o que é dado - aliás, não há outro acesso fenomenológico à doação senão o que é doado, o que aparece, o fenômeno. Em vez de supor o que é dado como um dado bruto, neutro, simplesmente aí, disponível e subsistente (o que torna o dado ininteligível), pensar a doação permite trazer à luz uma ambiguidade do dado, o seu caráter de surgir, advir. $\mathrm{O}$ dado implica um surgimento, um evento que o impõe ou pelo qual se impõe - isto é a doação (ED, p. 93). Se o dado é o que se impõe, a doação que o doa permanece dissimulada, enigmática; mas o fenômeno guarda um vestígio dela, precisamente por se dar. A doação do fenômeno exige um "si" do fenômeno, que impede que ele seja considerado o representante de algo outro, como já mencio- 
nei anteriormente. É importante insistir sobre isto, precisamente porque vejo nisso um modo de superar o idealismo de Husserl que consiste em reconduzir e reduzir toda a doação dos fenômenos à obra da consciência, retirando daquilo que é dado qualquer "em si". Certamente não nos é permitido pensar este "si" do fenômeno ingenuamente, como anterior à doação. Marion o articula com a intencionalidade, como o que lhe corresponde do ponto de vista do fenômeno, da coisa mesma.

O fenômeno só pode aparecer como tal, e não como a aparência de um outro que the fosse mais essencial do que ele próprio, ou seja, sem déficit de um em si, nem retratação de um número - e tal é precisamente o primeiro objetivo da fenomenologia - se perfurar o espelho da representação; o aparecer deve portanto subtrair-se (senão antes contradizer)ao imperialismo das condições a priori do conhecimento, conseguindo que o que aparece force o acesso à cena o mundo, avançando em pessoa, sem dublê, nem representante; este adiantar-se chama-se, do ponto de vista daquele que conhece, a intencionalidade; do ponto de vista da própria coisa, é chamado doação (ED, p. 101).

O "si" do fenômeno é precisamente aquilo que chega ao aparecer, mas não é atribuído à consciência ou ao sujeito. Marion diz que o aparecer do fenômeno não se impõe por este ter já um estatuto de objeto ou de ente; antes, estes advêm ao fenômeno pela simples aparição. O "si" do fenômeno provém da doação. A constituição e a síntese, da parte do pensamento, não instituem o fenômeno; o pensamento só pode compreender e constituir o que antecipadamente advém e se impõe, na contingência do seu surgir. A própria contingência do surgimento do fenômeno é definida por Marion pela sua relação com a doação, como um advir e um me tocar que caracteriza o dado; é significativo este desvincular a contingência do seu aspecto epistemológico, da incerteza do conhecimento (ED, p. 189). O surgimento do dado é um fato, ele encontra o seu sentido na sua facticidade, a partir da qual é possível também um conhecimento eventualmente certo dele. 
Ao se perguntar sobre os graus de doação, que tornariam inteligíveis as diferenças entre os diferentes entes, o autor pergunta sobre as possibilidades de a doação tornar possível a fenomenalidade, o que lhe permite novamente analisar os limites postos à doação nas filosofias da tradição. A sua convicção é que é sempre a metafísica aquela que limita as possibilidades, impondo algum tipo de razão, fundamento ou condições ao aparecer e não compreendendo as possibilidades a partir do próprio aparecer. Em Husserl, não há necessidade de nenhum princípio de razão suficiente, como em Leibniz, nem de algum princípio de possibilidade, como em Kant. A intuição é o princípio suficiente para os fenômenos, a sua fonte de fato e de direito. Ela se justifica, por sua vez, por pretender dar a origem incondicionada. E contudo, Marion mostra que ela mesma tem condições e limites na concepção de Husserl. O seu primeiro limite é o horizonte, exigido para a doação dos fenômenos: todos os vividos se encontram no fluxo de consciência, no qual os fenômenos são intencionados, antecipados e retidos, sem poderem abrir um imprevisto fenomenal radical, para além do polo intencional do objeto pré-visto e esperado. É a própria intuição, o preenchimento da intenção, que acontece na sucessão dos vividos e por isso reclama um horizonte e um polo objetivo delimitado nele. $\mathrm{O}$ segundo limite para a doação é o eu transcendental que, para Husserl, seria o próprio horizonte último. A intuição, assim limitada, é pobre e não se adequa perfeitamente à intenção - que em relação à intuição está em excesso - para satisfazer o ideal da evidência e a plenitude da doação do fenômeno; a evidência portanto permanece um ideal, realizado pelos fenômenos pobres - os da matemática e lógica - mas impossível para a percepção dos objetos reais. Ora, é uma decisão metafísica, segundo Marion, que remonta até Kant, a de exigir para a verdade, definida como adaequatio, o paralelo entre a intuição e conceito e, mais ainda, fazer da intuição, pela qual unicamente os fenômenos podem ser dados e ser assim pensados pelos conceitos, um limite para a extensão da doação dos fenômenos. Por esta opção metafísica, os fenômenos mais comuns e mais interessantes não se 
dão em plenitude, e o fenômeno lógico e matemático, pobre em intuição mas oferecendo certeza, é erigido em modelo de fenomenalidade.

A metafísica confirma assim seu nihilismo ao se regular sobre o paradigma dos fenômenos que não aparecem ou aparecem pouco e ignorando o paradigma daqueles que aparecem suficientemente para pretender o estatuto de coisas de pleno direito; ela os recusa na mesma medida em que eles exigem de aparecer (ED, p. 274).

É esta decisão metafísica, seguida pela fenomenologia de Husserl ao impor uma necessidade fenomenológica ao aparecer dos fenômenos - a necessidade de se inscreverem num horizonte delimitado e de se reduzirem ao estatuto de objetividade finita para serem constituídos por um eu finito - que define os fenômenos como condicionados e redutíveis. "As duas finitudes, do horizonte e do eu, encontram-se na finitude da própria intuição. Os fenômenos se caracterizam pela finitude da doação neles, que única lhes permite (e impõe) de entrar num horizonte e de se deixar reconduzir a um eu" (ED, p. 76). Encontramos aqui, portanto, uma explicação da delimitação da doação dos fenômenos ao modo de ser dos objetos, que foi um motivo de crítica de Marion à fenomenologia e à concepção de ser de Husserl desde as primeiras obras. Respondendo a esta concepção da doação limitada pela intuição, Marion opõe à penúria da intuição um excesso de intuição: o fenômeno saturado de intuição.

\section{3.}

Vista a partir da doação e do dado como fenômeno saturado, a concepção da subjetividade é necessariamente e radicalmente mudada. Evitando definir a subjetividade como ente, ou eu transcendental, ou Dasein, precisamente pela insuficiência das concepções fenomenológicas que postularam tais sentidos de subjetividade que estaria implicada na doação, para trazer à luz da reflexão a própria doação, Marion a define 
como aquele que recebe a doação, o adonado ${ }^{3}$ [adonné], o convocado ou o testemunha (VR, p. 171). Sua caracterização negativa passa precisamente pela crítica da função transcendental da subjetividade pela qual esta exerceria o papel da fundamentação ou fundação da experiência.

O ego, desprovido da sua púrpura transcendental, deve admitir-se tal como se recebe, como um adonado: aquele que se recebe a si mesmo daquilo que recebe, aquele a quem o que se dá de um si primeiro todo fenômeno - dá um mim segundo, o da recepção e da resposta. O ego guarda todos os privilégios da subjetividade, salve a pretensão transcendental de origem (DS, p. 54).

A subjetividade nem precede nem acompanha o aparecer como uma instância já estabelecida, não o constitui ou originariamente condiciona. O que caracteriza positivamente a subjetividade na doação é o fato de ser receptora, tanto de si mesma como dos fenômenos: recebendo a doação e convertendo-a em aparecer, tornando o dado visível ou permitindo-lhe aparecer, a subjetividade ao mesmo tempo se torna o que é, recebe a si mesma e aparece para si mesma. Não pode portanto funcionar como um fundamento transcendental, visto que é originariamente "contemporânea" à recepção do dado e originariamente posterior em relação ao apelo da doação; mais do que isso, é injustificada a concepção da subjetividade como posta através de uma autoposição originária: a subjetividade não é originariamente o eu que se põe, mas um mim que se recebe ao receber todo o resto, um sujeito em dativo, testemunhando irredutivelmente uma relação precedendo a individualidade. Daqui um sentido novo da facticidade da subjetividade: ela é feita do fato de ser convocada, fato sempre já consumado e dado no momento em que dele se toma consciência; este apelo é um dom da palavra à qual a subjetividade é a resposta: o homem é um "mortal dotado de palavra", tendo recebido o dom da palavra.

3 O tradutor para o português do Le visible et le révélé, J. Pereira, traduziu assim o termo francês adonné. (VR p. 170). 
Uma "inautenticidade" ou falta de originariedade, a impossibilidade de se identificar originariamente como um eu, é portanto característica da subjetividade (ED, p. 372 - 373).

Ora, esta função de receber-se e receber o dado dá à subjetividade contudo um lugar imprescindível na doação, o lugar em que a doação se mostra:

se tudo que se mostra deve para tal primeiramente dar-se, não basta entretanto que o dado se dê para que se mostre, porque às vezes a doação quase ofusca a manifestação. $\mathrm{O}$ adonado tem precisamente como função a de medir nele mesmo a distância entre o dado - que jamais cessa de se lhe impor e de impô-lo a ele - e a fenomenalidade - que só se completa enquanto e na medida em que a recepção chega a fenomenalizar ou, melhor, lhe deixa fenomenalizar-se. Esta operação - fenomenalizar o dado - cabe particularmente ao adonadohaja vista seu privilégio difícil de constituir o único dado no qual esteja em questão a visibilidade de todos os outros dados (DS, p. 58).

A operação de fenomenalizar ou converter o dado em fenômeno significa, para Marion em Étant donné e em De surcroît, da parte da subjetividade, opor uma resistência ao choque cru do dado, funcionar como um écran contra o qual o que é dado se choca e assim torna visível o dado e a subjetividade. Fenomenalizar é assim um revelar.

4.

Penso que a partir desta concepção da doação e da subjetividade como receptora do dado seja possível pensar o ser de um modo novo. Não encontrei a explicitação disto em Marion, pelo menos nas obras mencionadas e conhecidas por mim; creio que a razão seja o empenho primeiro do autor em mostrar a originariedade da doação em relação à ontologia e a toda a problematização do ser. A justificativa de retornar 
contudo à questão do ser está, em primeiro lugar, em Husserl não deixar de nomear o eu transcendental como ser, como "uma esfera infinita de ser de um tipo novo, enquanto esfera de uma experiência de tipo novo" (Hua I, par. 12, p. 66) e na sua insistência em considerá-lo diferente de todo o ser dos objetos mundanos: sua evidência "não coincide, sem mais, com a evidência acerca do ser dos múltiplos dados da experiência transcendental" (Hua I, par. 12, p. 67). A diferença em relação ao ser dos objetos se torna notável quando Husserl pensa o ser da subjetividade como o ser da vontade, e assim como um devir, um processo de tornar-se si mesmo, de constituição e de renovação de si, um processo voluntário orientado conscientemente para um ideal, para a ideia da sua realização no infinito. O ser da subjetividade é já em Husserl um processo atravessado pela tensão para algo para além de si, para a transcendência em direção a um télos, à perfeição e ao bem.

Em segundo lugar, a justificativa para repensar o ser está também numa ambiguidade não evidenciada até agora, encontrada nos textos de Husserl a respeito do ser da subjetividade, que lhe impede de considerar o ser da subjetividade apenas e unicamente como transcendental; a existência fática, empírica do eu se impõe com uma força própria mesmo após a redução dos fatos às essências e após a redução dos atos de constituição do ser do mundo ao fluxo fático da consciência transcendental. Como um exemplo paradigmático deste irrompimento da existência fática do eu que faz a redução pode ser citado o texto nr. 22 do terceiro volume sobre a intersubjetividade:

O eidos do Eu transcendental é impensável sem o Eu transcendental como fático. [...] Eu sou o fato originário neste processo, eu reconheço que à minha capacidade fática da variação da essência, no meu questionar fático, resultam estes conteúdos, próprios a mim, enquanto estruturas originárias da minha facticidade. E que eu trago em mim um núcleo do "originariamente acidental" nas formas de essência [...] (Hua XV, p. 385-386). 
A relação entre a essência do eu e o fato da existência do eu não se iguala à relação entre essência e fatos em geral: o fato de eu existir e pensar de fato, com toda a sua contingência, condiciona o pensamento da essência de um modo que se deixa associar ao conceito de advir, de Marion. Que este eu fático não possa ser pensado apenas como ser transcendental, provam-no as análises de Husserl sobre a necessidade de aparição de uma existência empírica do eu para a operação da constituição intersubjetiva do mundo objetivo: para poder haver posição do mundo real pela consciência, portanto nexos de consciência tais que motivem atos de posição do mundo, é necessário um eu realmente existindo no mundo. "A existência real de uma coisa, portanto de um mundo efetivo, exige [...] um eu atual com conteúdo específico, uma consciência realmente existente, com experiências reais e teses de experiência reais" (Hua XXXVI, nr. 5, p. 78). A subjetividade tem, portanto, irredutivelmente um ser duplo, o ser absoluto e o ser do aparecer (Hua VIII, p. 508). É certo que a primazia cai em Husserl sempre sobre o ser absoluto da subjetividade que apenas secundariamente se mundaniza, ou seja, fenomenaliza. Contudo, se as razões metafísicas que Husserl oferece para esta primazia não convencem, é necessário retornar à pergunta sobre a particularidade do ser da subjetividade. Sobretudo porque a partir do ser da subjetividade se decide também o ser do mundo, o sentido de todo o ser que em Husserl guarda uma marca idealista.

Uma outra observação pode ser feita ainda em defesa da pergunta sobre o sentido originário do ser da subjetividade. Quem está familiarizado com a reflexão de Levinas, encontra no pensamento de Marion um desenvolvimento, talvez uma universalização daquilo que significa para Levinas a saturação da intuição exclusivamente na relação com o Outro para o fenômeno em geral e a implicação disto para a subjetividade. Ora, precisamente em Levinas o ser da subjetividade - e a operação que caracteriza esse ser, ou melhor, a operação de constituir o sentido de tudo o mais e de o reduzir a si mesmo - está problematizada do ponto de vista da doação do Outro, mas não do ponto de vista universal, embora Levinas 
reconheça uma certa cooriginariedade do ser e dos outros. Considerar o ser do ponto de vista da doação do ser, a meu ver, muda radicalmente o sentido do ser, por permitir pensá-lo na sua relação com o Bem como fonte de sentido, do qual o ser é excluído na consideração de Levinas.

O mundo, o ser e o Outro são para Marion variações do que é dado e devem portanto ser pensados a partir da doação, ou seja, reduzidos e reconduzidos ao conceito originário da doação na sua dobra com o dado. Ora, apenas metodologicamente - pela redução-podemos suspendê-los, reduzi-los, dissociá-los entre si e da doação, em vista do desvelar das relações mais originárias de sentido. $\mathrm{O}$ fenômeno pleno, e sobretudo o sentido pleno da subjetividade, contudo, exige que sejam pensados na sua doação indissociável sempre já efetuada. Isto nos obriga a pensar a doação nas suas figuras concretas do que é dado, para também não resultar em alguma fórmula vazia de dado, para evidenciar não apenas uma primazia do estatuto fenomenológico do sentido, mas a plenitude do sentido, pelo menos como possibilidade.

Neste sentido, podemos perguntar-nos por que insistir em abolir diferenças metafísicas significativas, como a de essência e existência, ou ser pensado e ser efetivo e não simplesmente pensá-las mais profundamente a partir dos novos elementos que a fenomenologia da doação nos oferece? Creio que a fenomenologia não precisa ter medo de nenhuma questão metafísica e não precisa ocupar-se em nivelar distinções metafísicas. ${ }^{4}$ A existência ou o ser da subjetividade, que irrompe como um

4 Um exemplo de uma tal reflexão sobre o ser a partir da fenomenologia, sem contudo explicitamente recorrer ao conceito da doação, é a reflexão de Edith Stein, anterior à de Marion. Na obra Endlichesundewiges Sein, a autora faz uma análise fenomenológica do ser da subjetividade que encontra o seu próprio ser como a vida transcorrendo temporalmente: o ser do eu não pode ser separado dos atos intencionais nos quais o eu vive, e estes lhe revelam o ser como sendo atual, isto é presente, efetivo, porém é puntiforme, fluente, cercado por um nãoser do que não é mais e do que não é ainda. Precisamente neste caráter do ser do eu, que é pleno apenas no momento em que existe e por isso não totalmente pleno, porque momentâneo, temporal, revela-se também a ideia de um ser atual 
fato o pensamento transcendental, testemunha a doação e não se deixa reduzir ao que o pensamento é capaz de constituir.

Como podemos pensar, a partir da doação, a subjetividade concretamente, isto é, no seu ser? Esta reflexão ainda deve ser feita e aqui não posso apresentar senão alguns apontamentos superficiais, carentes de aprofundamento e de maior unidade interna. Apresento-os pois, mesmo na sua penúria, como conclusão deste escrito.

A subjetividade, juntamente com o dado ou dom da palavra e do sentido, recebe também a si mesma, isto é, o seu próprio ser, e o dom do Outro, dados dos quais não pode considerar-se dona, origem ou fundamento. O ser, enquanto dado, não permite a indiferenciação entre o que a subjetividade é e seu ato de ser que sempre atualiza algum aspecto seu; a existência, enquanto ato, mesmo empírica ou real, aponta para um excesso no sentido do ser, que não pode ser reduzido ao ser do objeto constituído, ao ser para a consciência e ao ser da consciência transcendental. É um primeiro dom, porque há nele um tender para algo outro além do sujeito, para o Outro, para o bem e para o Infinito, do qual a presença empírica no

puro que não tem não-ser, que não é temporal, mas eterno e por isso pleno em todos os instantes. A autora escreve que é forçoso caracterizar o ser do eu, tal como o eu o encontra, como um ser recebido, como dom. "O ser do eu é um tal ser que se reaviva de um a outro momento. Não pode 'parar', porque escorre 'incessantemente'. Por isso nunca chega realmente à posse de si. Por isto necessitamos de definir o ser do eu, este presente vivo constantemente mutável, como um ser recebido. Ele é posto em existência e de momento em momento nela mantido. [...] Todo finito é um ser posto no ser e nele conservado e por isso não capaz a partir de si mesmo de pôr e manter o ser. [...] Meu ser, tal como eu o encontro e me encontro nele, é um ser nulo; não sou a partir de mim mesmo e a partir de mim mesmo sou nada, em cada momento estou perante o nada e devo de momento em momento ser presenteado (dotado [beschenkt]) com o ser. E contudo o ser nulo é ser e eu toco com ele em cada momento a plenitude do ser" (STEIN, 2006, p. 57). Não posso deixar de mencionar aqui também um outro autor, que explicitamente pensou o ser como dom, antes de Marion, embora não na perspectiva fenomenológica: Claude Bruaire, por exemplo na obra La force de l'esprit. 
mundo é feita porta-voz, testemunha - fato do qual não posso retrair-me ou evadir-me. O sentido do meu ser não é portanto originado em mim, tampouco como o sentido do Outro: como dom, ele me apela para uma responsabilidade para comigo mesmo e para com os outros e para uma resposta na qual posso encontrar a mim mesmo como dado aos outros e originariamente intencionado para a transcendência mais radical. Esta responsabilidade diz respeito à existência, minha e dos outros, real, isto é, mundana, e ao sentido que atravessa esta existência e a transcende.

\section{Conclusão}

Que o aparecer dos fenômenos implica a doação, foi certamente visto por Husserl; na interpretação de Marion, contudo, Husserl não viu a doação para além da doação dos objetos, na qual está implicada a subjetividade ou a consciência constituinte que marca o sentido dos objetos pelo seu jogo de intenção e intuição. Isto está a meu ver relacionado em Husserl com a concepção do ser da subjetividade como absoluto e do ser da realidade como inteiramente dependente da subjetividade, com a concepção do ser como ser conhecido e posto pela consciência. No olhar de Marion sobre a doação esta se deixa pensar mais livre da finitude da subjetividade. Por isso me parece possível pensar por ela o ser, primeiramente o ser da subjetividade, no seu sentido mais radical do que aquele que o idealismo oferece. Certamente a participação do adonado na aparição dos fenômenos pode e deve ser pensada ainda melhor, na sua diferença com o eu transcendental. Penso que seja precisamente o fato de receber-se, no seu ser, que torna possível sublinhar esta diferença. No fim, penso que haja também em Husserl sinais deste sentido mais radical, do exceder da doação do ser em relação à constituição, ao operar da subjetividade absoluta. Também nele encontrou expressão o maravilhar-se com o fato de que algo, o ser e muito mais, é dado, o fato que precisamente exige ainda ser pensado. 


\section{REFERÊNCIAS}

HUSSERL, Edmund. Cartesianische Meditationen und Pariser Vorträge. Stephan Strasser (Hrsg). Husserliana I. The Hague: MartinusNijhoff, 1973.

. Die Idee der Phänomenologie. Fünf Vorlesungen. Walter Biemel (Hrsg). Husserliana II. The Hague: Martinus Nijhoff, 1950.

. Erste Philosophie (1923/24). Zweiter Teil: Theorie der phänomenologischen Reduktion. Rudolf Boehm (Hrsg.). Husserliana VIII. The Hague: Martinus Nijhoff, 1959.

. Ideen zu einer reinen Phänomenologie. Erstes Buch: Allgemeine Einführung in die reine Phänomenologie. Karl Schuhmann (Hrsg). Husserliana III.The Hague: Martinus Nijhoff, 1976.

. Transzendentaler Idealismus. Texte aus dem Nachlass (1908 - 1921). Robin D. Rollinger (Hrsg.). Husserliana XXXVI. Dordrecht: Kluwer Academic publishers. 2003. http://dx.doi.org/10.1007/978-94007-1062-7

. Zur Phänomenologie der Intersubjektivität. Texte aus dem Nachlass. Dritter Teil: 1929-1935. Iso Kern. (Hrsg.) Husserliana XV. The Hague, Netherlands: MartinusNijhoff, 1973. http://dx.doi. org/10.1007/978-94-010-2474-7

MARION, Jean-Luc. De surcroit. Études sur les phénomènes saturés. Paris: PUF, 2001. (DS).

. Étant donné. Essai d'une phénoménologie de la donation. 2. éd. Paris: PUF, 1998. (ED).

. Le visible et le révélé. Paris: Les Éditions du Cerf, 2005. Tradução portuguesa. O visível e o revelado. Tradução de Joaquim Pereira. São Paulo: 2010. (VR). 
. Réduction et donation. Recherches sur Husserl, Heidegger et la phénoménologie. Tradução inglesa: Reduction and Givenness. Investigations of Husserl, Heidegger and Phenomenology. Tradução de Thomas A. Carlson. Evanston: Northwestern University Press, 1998. (RD)

STEIN, Edith. Endliches und ewiges Sein. Versuch eines Aufstiegs zum Sinn des Seins. Freiburg: Herder, 2006.

Data de registro: $12 / 09 / 2016$

Data de aceite: $26 / 10 / 2016$ 